Benjamin Scheller

Die Stadt der Neuchristen 
Europa im Mittelalter

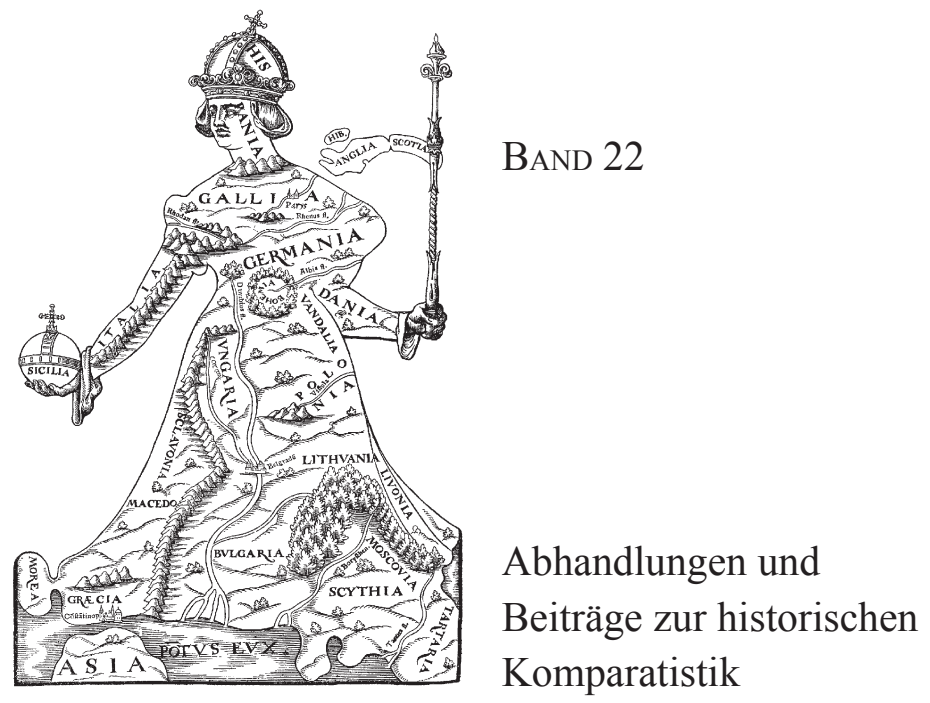

Herausgegeben von

Michael Borgolte und Wolfgang Huschner 
Benjamin Scheller

\section{Die Stadt der Neuchristen}

Konvertierte Juden und ihre Nachkommen im Trani des Spätmittelalters

zwischen Inklusion und Exklusion

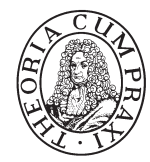

Akademie Verlag 
Gedruckt mit Unterstützung der Alexander von Humboldt Stiftung

Einbandgestaltung: hauser lacour

Bibliografische Information der Deutschen Nationalbibliothek

Die Deutsche Nationalbibliothek verzeichnet diese Publikation in der Deutschen Nationalbibliografie; detaillierte bibliografische Daten sind im Internet über http://dnb.d-nb.de abrufbar.

Library of Congress Cataloging-in-Publication Data

A CIP catalog record for this book has been applied for at the Library of Congress.

Dieses Werk ist urheberrechtlich geschützt. Die dadurch begründeten Rechte, insbesondere die der Übersetzung, des Nachdrucks, des Vortrags, der Entnahme von Abbildungen und Tabellen, der Funksendung, der Mikroverfilmung oder der Vervielfältigung auf anderen Wegen und der Speicherung in Datenverarbeitungsanlagen, bleiben, auch bei nur auszugsweiser Verwertung, vorbehalten. Eine Vervielfältigung dieses Werkes oder von Teilen dieses Werkes ist auch im Einzelfall nur in den Grenzen der gesetzlichen Bestimmungen des Urheberrechtsgesetzes in der jeweils geltenden Fassung zulässig. Sie ist grundsätzlich vergütungspflichtig. Zuwiderhandlungen unterliegen den Strafbestimmungen des Urheberrechts.

(C) 2013 Akademie Verlag GmbH

www.degruyter.de/akademie

Ein Unternehmen von De Gruyter

Gedruckt in Deutschland

Dieses Papier ist alterungsbeständig nach DIN/ISO 9706.

ISBN 978-3-05-005977-8

eISBN 978-3-05-005978-5 